\title{
A RELAÇÃO TEORIA E PRÁTICA NA FORMAÇÃO DO PROFESSOR UNIVERSTTÁRIO: princípios e metodologia
}

\author{
The relation of the practical and of the theory \\ in the formation of the university teacher: \\ principles and methodology
}

Pura Lúcia Oliver Martins*

\section{Resumo}

Este artigo apresenta o projeto vivido na organização/produção de uma metodologia denominada Sistematização coletiva do conhecimento, a qual vem sendo investigada pela autora nos últimos vinte anos. Em sua articulação com o contexto histórico e cultural, o eixo epistemológico de sua organização, e os princípios teóricos que emergiram da Didática prática, essa metodologia vem sendo efetivada com grupos de professores dos três níveis do ensino: fundamental, médio e superior, nos vánios sistemas estaduais de educação, em todo o país. Tal prática é pautada num processo coletivo de pesquisa - ensino, que sistematiza a prática pedagógica desenvolvida nas instituições educacionais, analisa-a criticamente e propõe novas práticas. Assim, o trabalho visa a contribuir por um lado com a prática dos professores envolvidos no processo e por outro lado com a Didática, levando princípios relativos ao seu campo de conhecimento e ao processo metodológico para seu ensino, na formação docente.

Palavras-chave: Pesquisa, Metodologia, Conhecimento, Didática, Ensino, Sistematização.

* Professora do Mestrado em Educação e do Curso de Pedagogia da PUCPR.

Pontifícia Universidade Católica do Paraná - Mestrado em Educação, Rua Imaculada Conceição, 1155, Prado Velho, Curitiba - PR, CEP 80215-901.

E-mail: pura@rla01.pucpr.br 


\section{Abstract}

This article presents the project lived in the organization and production of a called methodology, collective Systematization of the knowledge, which comes being investigated for the author in last the twenty years. In its joint with the historical and cultural context, the theory of the knowledge axle of its organization and the theoretical principles that had emerged of the practical Didactics, this methodology comes being accomplished with groups of professors of the three levels of education: basic, average and superior, in the some state systems of education, in all the country. Such practical is based in a collective process of research - education, that it systemize practical the pedagogical one developed in the educational institutions, analyzes it criticizes and considers new practical. Thus, the work aims at to contribute on the other hand with practical of the involved professors in the process and on the other hand with the Didactics, leading the relative principles to its field of knowledge and the forms methods process for its education, in the teaching formation.

Keywords: Search, Methodology, Knowledge, Didactics, Systematization

“... uma resposta nunca merece uma reverência. Mesmo que seja inteligente e correto, nem mesmo assim você deve se curvar a ela.(...) Quando você se inclina, você dá passagem,e a gente nunca deve dar passagem para uma resposta (...) A resposta é sempre um trecho do caminho que está atrás de você. Só uma pergunta pode apontar o caminho para frente."

(JOSTEIN, 1997 p.27)

A formação pedagógica do professor da Educação Superior tem se constituído em uma preocupação constante nas universidades entre seus agentes (professores e gestores). Ao mesmo tempo, tem ocupado cada vez mais espaço no meio acadêmico entre os estudiosos da área.

É crescente a demanda por cursos de formação pedagógica para profissionais das diferentes áreas do conhecimento que atuam no magistério superior. Disciplinas pedagógicas têm se constituído estudo obrigatório na maioria dos programas de Pós-graduação stricto sensu em todo o país.

Na PUCPR, por exemplo, o Mestrado em Educação oferece a disciplina Processos Pedagógicos na Educação Superior para todos os programas de mestrado e doutorado da Universidade, em caráter obrigatório. Já o programa de pós-graduação em Educação da UFMG atende a mais de 46 programas de mestrado e doutorado da universidade oferecendo a disciplina Didática do Ensino Superior em caráter optativo ou obrigatório de acordo com os programas das diferentes áreas do conhecimento. Independentemente do caráter obrigatório ou optativo da disciplina, o que se observa é um interesse crescente dos profissionais das diferentes áreas do conhecimento pela formação pe- 
dagógica por ela oferecida. ${ }^{1}$ Esse interesse se confirma com a crescente demanda de matrícula isolada na disciplina, por professores universitários que não estão cursando ou já concluíram a pós-graduação.

O que estaria mobilizando esses profissionais a buscar a formação pedagógica? E mais, que questões da prática pedagógica esses profissionais levantam? Que alternativas apontam? Que caminhos percorrem nas suas lidas diárias com 0 ensino?

Para encaminhar uma reflexão acerca dessas questões postas pela prática do docente universitário hoje, no presente artigo, apresento uma breve retrospectiva da produção e da sistematização da metodologia que denomino Sistematização Coletiva do conhecimento, a qual venho investigando nos últimos vinte anos em sua articulação com o contexto histórico, o eixo teóricoepistemológico de sua organização e os princípios orientadores que emergiram da Didática prática no período que compreende os anos de 1985 a 2000. (MARTINS, 2002).

A relação teoria-prática na formação do professor tem sido a preocupação central do trabalho que desenvolvo, há duas décadas, com professores dos três níveis de ensino. Tal prática é pautada num processo coletivo de pesquisa-ensino que problematiza a prática pedagógica desenvolvida nas instituições educacionais, analisa-a criticamente e propõe novas práticas. Assim, busco contribuir, por um lado, com a prática dos professores envolvidos no processo e, por outro, com a área da Didática, levantando princípios relativos ao seu campo de conhecimento e ao processo metodológico para o seu ensino, na formação docente.

No início dessa trajetória, desenvolver um processo de ensino de Didática mais articulado com a prática das escolas de Ensino Fundamental e Médio, considerando-se a lógica, os interesses e as necessidades práticas das classes trabalhadoras, era o grande desafio. No contato com os professores e suas práticas, colocando-os como atores e autores do processo de ensino, vivenciando esse processo, refletindo acerca dele e sistematizando-o coletivamente, outra problemática foi se delineando e tomando contornos mais claros ao longo desse período, pois de acordo com Martins (1985):

o professor, no processo contraditório que enfrenta entre a formação acadêmica recebida e a prática na sala de aula, gera uma Didática prática, germe de uma possível teoria pedagógica alternativa. Essa Didática prática, presente no trabalho do professor, implica pressupostos teóricos que precisam ser captados, explicitados e estruturados teoricamente...

Tal problemático, não fora "previsto" quando iniciei minha trajetória de pesquisa-ensino em 1983, ainda no Mestrado. No entanto, deparei-me com 
professores que, ao desempenharem suas atividades pedagógicas, tomavam iniciativas distintas para enfrentar as contradições próprias da organização da escola naquele momento histórico. A essas iniciativas convencionei denominar Didática prática, entendendo que nessa Didática prática poderia estar contida a gênese de uma possível teoria pedagógica alternativa e comprometida com as classes trabalhadoras.

Durante todos esses anos, o contato direto e permanente com grupos de professores dos três níveis de ensino, oriundos de várias partes do País, ${ }^{2}$ permitiume captar, problematizar e analisar a Didática prática que estava sendo forjada pelos professores no interior das escolas. Foi-me então colocado outro desafio: aprofundar o entendimento dessa Didática prática, ${ }^{3}$ procurando investigar como ela se desenvolveu no cotidiano da escola, como ela se explica nos seus determinantes mais profundos, o que ela expressa, que contribuições pode trazer para a Didática na área do conhecimento e nos processos de ensino.

Desde então, minhas pesquisas têm se pautado em dois pressupostos básicos. Em primeiro lugar, penso que a sistematização da literatura da área expressa a didática como uma prática pedagógica que decorre da relação social básica do sistema capitalista num momento histónico determinado. As formas como as classes sociais se relacionam vão se materializar em técnicas, processos, tecnologias, inclusive os processos pedagógicos que se realizam mediante uma dada relação pedagógica. Assim, a reconstrução do conhecimento da Didática não se faz por meio de reflexões exclusivamente teónicas, mas emerge das contradições presentes na prática de nossas escolas, expressando a prática de seus agentes ao vivenciarem essas contradições. Em segundo lugar, acredito que os conflitos sociais são capazes de gerar processos pedagógicos voltados para a lógica e as necessidades práticas das classes trabalhadoras.

Tomo como eixo central as relações sociais, porque entendo que a teoria expressa uma relação, sendo essa ao mesmo tempo material e social: material, porque se dá no local de trabalho, nas ações concretas da produção da própria vida das pessoas e independe dos pensamentos, das representações; e social, porque essa produção não se faz de forma individual, mas se faz de forma coletiva. Os homens estabelecem relações entre si, são relações sociais estabelecidas no processo de produção. Essa prática não é direta, mas se realiza mediante instituições que os homens criam na sua ação transformadora, mediante situações práticas. Bernardo (1977, p. 86) afirma que:

...uma teoria é sempre a teoria de uma prática e não de qualquer realidade material que transcende o processo dessa prática, nem dessa realidade enquanto não praticada. $\mathrm{O}$ homem não reflete sobre o mundo, mas reflete $\mathrm{a}$ sua prática sobre o mundo. 
Assim, minhas pesquisas fundamentam-se no eixo epistemológico da teoria como expressão de ações práticas e, sem perder de vista o primeiro desafio, adoto como objeto de estudo a Didática prática forjada pelos professores dos três níveis de ensino no interior da instituição escolar, no enfrentamento das contradições da prática.

No contato direto e permanente com professores ministrando as disciplinas pedagógicas em cursos de pós-graduação lato e stricto sensu, em diversas regiões do país, desenvolvi e sistematizei uma metodologia de ensino na perspectiva da sistematização coletiva do conhecimento. De acordo com Martins (2003), nesse processo de pesquisa-ensino os participantes expressam as experiências pedagógicas vividas por eles nas suas instituições de ensino e problematizam-nas, buscando a superação dos problemas postos por essa prática. Assim, ao mesmo tempo em que avançam na solução dos problemas da sua prática pedagógica, fornecem elementos para a sistematização de novos conhecimentos para a área e participam dessa elaboração.

Embora minha prática na condição de professora-pesquisadora abranja a formação pedagógica de professores dos três níveis de ensino, nos últimos anos focalizo o professor da Educação Superior e sua busca de articulação entre teoria e prática na formação do profissional no nível do Ensino Superior. ${ }^{4}$

Para superar a dicotomia entre teoria e prática presente na Educação Superior, o grande desafio é desenvolver uma prática na formação do professor, que ultrapasse as relações sociais usualmente estabelecidas, expressas na transmissão-assimilação de conhecimentos. Isto porque essas práticas têm favorecido um avanço no discurso dos professores, sem, contudo, apresentar mudanças substantivas nas suas práticas pedagógicas.

A distância entre os discursos mais progressistas acerca dos avanços nas propostas de ensino, sobretudo a partir da década de 80, e 0 ensino implementado junto dos alunos, tem apresentado contradições muito freqüentes nas práticas dos professores em geral. Assim, partindo do pressuposto de que "a escola educa mais pela forma como organiza o processo de ensino do que pelos conteúdos ideológicos que veicula através desse processo" conforme citado em Martins (1989, p. 90), desenvolvo um trabalho de pesquisa-ensino que tem me permitido propiciar aos professores e/ou futuros professores, a vivência e análise críticas de um processo metodológico que procura alterar as relações sociais estabelecidas no seu interior. Um ponto chave dessa metodologia "encontra-se na alteração do processo de ensino e não apenas na alteração do discurso a respeito dele. (...) Não se trata de falar sobre, mas de vivenciar e refletir com ..." (MARTINS, 1989, p.175, grifos nossos)

Considero este trabalho como um processo de pesquisa-ensino porque, de um lado, a sua forma de realização constitui uma pista para redimensionar as práticas de ensino numa perspectiva de sistematização coletiva 
do conhecimento. É ensino. Por outro lado, possibilita a vivência de um processo de investigação de ação-reflexão-ação pelo qual a Didática prática que está ocorrendo nas escolas se manifesta, é problematizada, explicada e compreendida nos seus determinantes, favorecendo a elaboração de propostas concretas de ação. Tudo isso, com o intuito de abrir novos caminhos numa perspectiva transformadora, para que ocorra uma sistematização coletiva de novos conhecimentos, gerados a partir de novas práticas, acerca do objeto de estudo. É pesquisa.

Assim, ocorrem mudanças substantivas nas relações sociais usualmente estabelecidas nos processos de pesquisa-ensino, que valorizam o espírito de colaboração, a solidariedade, as relações coletivas e favorecem o intercâmbio entre todos os envolvidos no processo, tendo em vista a resolução dos problemas práticos que vão surgindo ao longo de todo o processo.

A partir da sistematização da Didática prática desenvolvida pelos professores ao longo desse período, e da análise das reflexões teóricas que ocorreram entre os grupos de Didática e Prática de Ensino nos seus encontros, além de teses e dissertações relativas ao ensino, delineiam-se três momentos fundamentais. Esses momentos, com ênfases específicas, não se anulam, mas se interpenetram e devem ser entendidos como uma parte de um todo. 0 primeiro enfatiza a questão da Dimensão política do ato pedagógico - 1985/ 88; o segundo caracteriza-se pela ênfase na Organização do trabalho na escola - 1989/93; o terceiro, tem como elemento central a questão da Produção e sistematização coletivas do conhecimento - 1994... A caracterização desses três momentos tem como critério as questões recorrentes na prática dos professores no período e sua expressão teórica nas reflexões desenvolvidas no interior das universidades, quer em encontros científicos, quer nas produções de dissertações e teses relativas ao ensino.

O primeiro momento, que compreende os anos 1985/88, caracterizase por intensa discussão acerca da Dimensão política do ato pedagógico. Esse período é marcado por intensa participação social. Os movimentos sociais que ocorreram no Brasil, no final da década de 70 e primeira metade da década de 80, consolidaram novas formas de organização e mobilização que vão repercutir na escola. Os grupos sociais se definem como classe e passam a dar ênfase à problemática política. Os professores, no seu dia-a-dia, na sala de aula e na escola, reclamam da predeterminação do seu trabalho por instâncias superiores, e querem participar das decisões acerca dele. Essa participação tem um caráter eminentemente político.

O segundo momento compreende o período de 1989/93 e tem sua centralidade na Organização do trabalho na escola. Marca esse período a intensificação das alterações do sistema organizacional da escola. Os movimentos sociais, que consolidaram novas formas de organização e mobilização, 
foram se desenvolvendo à revelia e alheios às instituições - sindicatos, partidos políticos - e às formas tradicionais de organização trabalho, chegando a mudanças não só dessas instituições, como também, e sobretudo, a mudanças, ainda que embrionárias, nas próprias relações de produção. Nesse processo, os grupos sociais se definem como classes e uma nova ordem social se configura. Nesse momento, os professores já se compreendem e se posicionam como trabalhadores assalariados; organizam-se em sindicatos, participam de movimentos reivindicatórios. No interior da organização escolar, tentam alterar as relações sociais estabelecidas, burlando as normas e agindo de maneira diferente daquela que é prescrita pela escola. Também é redefinido o papel do especialista que já não pode mais assumir o papel de controlador. Torna-se necessário desenvolver trabalhos mais coletivos. Colocar-se o supervisor junto aos professores e não acima deles é um imperativo para a luta por um processo de ensino que atenda os interesses e necessidades práticas da clientela oriunda das classes trabalhadoras. É um período de transição em que os professores vão tomando iniciativas que possam vir a consolidar novas formas de organização.

Já o período compreendido entre 1994/2000 volta-se para as questões de produção e sistematização do conhecimento. A ênfase na problemática do aluno como sujeito vai se aprofundando à medida que se verificam alterações no interior da organização escolar por iniciativa de seus agentes. $\mathrm{O}$ aluno é concebido como um ser historicamente situado, pertencente a uma determinada classe, portador de uma prática social com interesses próprios e de conhecimento adquirido nessa prática. Tudo isso não pode mais ser ignorado pela escola. A tônica desse momento recai na problemática do ensino como processo de produção e sistematização coletivas de conhecimento. Esse momento se relaciona com os anteriores por meio da problemática da interdisciplinaridade que continua sendo uma questão importante. Em decorrência, põe em evidência a importância da articulação teoria-prática na organização da Educação Superior. Daí a busca de novas possibilidades para a organização do ensino e a crescente demanda dos profissionais das diferentes áreas do conhecimento que atuam na docência do Ensino Superior, pela formação pedagógica. Em última análise, esses professores buscam compreender os determinantes da prática pedagógica que desenvolvem e que já não respondem às exigências do momento atual na Universidade.

Atenta a essa problemática e colocando minha prática num processo de pesquisa-ensino, de um universo de aproximadamente cinco mil professores dos diversos níveis de ensino e de diferentes regiões do país com os quais trabalhei nesse tempo, é possível sistematizar alguns princípios orientadores para o ensino superior numa dimensão mais coletiva e de articulação teoriaprática. 
Da sistematização e análise crítica da Didática prática, forjada pelos professores no enfrentamento das contradições de suas práticas pedagógicas, algumas contribuições podem ser retiradas para a área da Didática na formação do professor, tanto no nível de conhecimento quanto no nível dos processos de ensino. Essa Didática prática expressa a pedagogia gerada no interior dos movimentos sociais nesse percurso histórico. Assim, a prática nos revela nesse momento histórico alguns princípios, que procuro analisar a seguir.

\section{Da vocação prescritiva a um modelo aberto de œonstrução de novas práticas}

O processo de pesquisa-ensino adotado para esse estudo configura uma concepção de conhecimento que dá um passo à frente em relação aos modelos anteriores. Trata-se de um processo metodológico pautado numa concepção de conhecimento que tem a prática como elemento básico, fazendo a mediação entre a realidade e o pensamento. Ou seja, enquanto nos modelos mais usuais trabalha-se com dois elementos: realidade/ pensamento, esse modelo trabalha com três níveis, quais sejam: realidade, ação sobre a realidade e pensamento decorrente dessa ação prática. Entre realidade/pensamento se introduz um elemento intermédio que é a ação prática sobre a realidade, dela decorrendo a teoria, não como essência, não como verdade que vai guiar a ação prática, mas como expressão de uma relação, de uma ação sobre a realidade, que pode indicar caminhos para novas práticas; nunca guiá-la. Desse princípio básico, delineia-se um modelo aberto de Didática que vai além de "compreender o processo de ensino em suas múltiplas determinações para intervir nele e reorientá-lo na direção política pretendida". (MARTINS, 1989, p. 76). Ela vai expressar a ação prática dos professores, sendo uma forma de abrir caminhos possíveis para novas ações. Ao se trabalhar com os professores problematizando e analisando suas práticas, está se produzindo um novo conhecimento. Esse novo conhecimento não vai se constituir num guia da ação prática, mas apontará possíveis formas de novas práticas. Esse é um princípio fundamental para a Didática.

Da transmissão à produção do onhecimento: pesquisa-ensino, uma unidade

Do princípio aludido acima, decorre uma questão básica para a Didática que terá como função criar condições e preparar o futuro professor e/ou professores em serviço, para que eles, no próprio processo de trabalho, passem a criar, a produzir novos conhecimentos. Nesse sentido, à medida que os professores começam a produzir e a ter perspectivas distintas da recepção e da apropriação do conhecimento, eles vêem a possibilidade de "apropriação" com outros olhos, porque redefinem a prática, na prática. Por outro lado, esse processo de trabalho em que o professor vai caracterizando e problematizan- 
do sua prática pedagógica, analisando, refletindo, criando novas possibilidades de práticas, produzindo conhecimentos acerca dessas práticas, socializando esses conhecimentos, inclusive por meio da escrita, ${ }^{5}$ é também uma atividade de pesquisa. No próprio processo de trabalho, eles passam a criar e a produzir novos conhecimentos, são atores e autores que se ensinam a si próprios e vão aprendendo num processo coletivo, redefinindo a prática.

Para que isso seja possível, torna-se necessário redimensionar as formas de relações sociais estabelecidas no interior da escola capitalista, buscando relações sociais mais coletivas e solidárias que favoreçam a produção e sistematização de novos conhecimentos. As formas de relacionamento são elementos chave do processo. Mediante relações sociais cooperativas, coletivas, passa-se a ter uma nova relação com o conhecimento. Isso possibilita ao professor começar a criar, a produzir coletivamente. Em decorrência, tudo aquilo que for materialização de conhecimento, tudo aquilo que for saber sistematizado passa a ser visto, nesse processo, como um objeto a ser trabalhado e não simplesmente apropriado de forma mecânica. Assim, a Didática há que levar em consideração a questão das relações sociais como elemento chave do processo, no qual as pessoas criem, produzam conhecimentos coletivamente.

Das relaøões hierárquico/individualistas para relaøões sociais coletivas e solidárias

Assim, outro princípio fundamental para a Didática será entender a relação pedagógica como relação social, como o elemento definidor das várias possibilidades de relação pedagógica, das várias formas de relação pedagógica e a relação social básica existente na sociedade. É essa relação social básica que determina como vão ocorrer as diferentes práticas, como se caracteriza a relação pedagógica em diferentes momentos históricos.

Das questões emergentes da prática dos professores ao longo do período investigado, duas se destacam como fundamentais e intimamente relacionadas: a questão da relação conteúdo-forma que valoriza a prática dos alunos como ponto de partida e coloca-a como questão central do processo de ensino; a reorganização das condições de trabalho vigentes na organização da escola, ampliando a participação de professores e alunos nas decisões acerca do processo de ensino que realizam. Essas mudanças, que vão ocorrendo no interior da organização escolar, indicam a necessidade de redimensionar as relações sociais ali estabelecidas, tanto no nível da escola como no nível da sala de aula.

Penso, ainda, que a problemática colocada pela Didática prática dos professores não se limita a buscar a melhor técnica, a melhor metodologia, o melhor conteúdo, a melhor forma de transmitir tudo a todos em menor tempo. 
O parâmetro passa a ser, não o conteúdo, mas a relação, a forma como se realiza essa situação prática. A Didática prática vislumbra uma concepção de ensino, uma concepção de didática que leve em consideração a forma da relação social, alterando, de forma prática, as relações sociais no interior da organização escolar, que possibilitará novas formas de relação com o conhecimento. Em função de como se dão as relações entre os agentes da escola, obtém-se uma forma de realização do ensino, da relação pedagógica frente ao conhecimento. Aqui está mais um princípio para a Didática: a mudança nas formas de relação social coloca possibilidades infinitas de realização do ensino, uma vez que ultrapassa a relação linear entre conteúdo-forma e pontua uma perspectiva de conteúdo-forma numa relação de causalidade complexa.

Da relação conteúdo-forma numa perspectiva linear de causa-efeito, para uma perspectiva de causalidade complexa

Nas suas práticas de luta, as classes trabalhadoras mostram novas formas de organização e novas formas de relação com o conhecimento, invertendo-se a concepção de conhecimento no qual a teoria é guia da ação prática. Inverte-se a relação: a prática não é guiada pela teoria, pois a teoria vai expressar a ação prática dos sujeitos. Ou seja, são as formas de agir que vão determinar as formas de pensar dos homens, as teorias, os conteúdos. A base do conhecimento é a ação prática que os homens realizam pelas relações sociais, mediante instituições. A forma como os homens agem é que vai definir como será o conhecimento, como será a visão de mundo.

Nessa perspectiva, na relação conteúdo-forma, o ponto de partida é um problema prático que ultrapassa a lógica reducionista de causa-efeito (conteúdo determinando a forma ou vice-versa). A relação conteúdo-forma passa a ser entendida numa relação de causalidade complexa, em que "O determinado não é concebido como expressão do determinante, porque a ação deste consiste em marcar a amplitude da ação do determinado, e não sua forma de realização". (BERNARDO, 1977, p. 60). Ou seja, um problema prático, tomado como ponto de partida para o ensino, não se constitui numa causa única que provoca um efeito único previsível, mas abre um campo enorme de possíveis resultados, pressupondo novas relações professor-aluno, professor-professor, novas relações organizacionais no interior da escola, novas relações frente ao conhecimento.

Nessa nova forma de entendimento da relação conteúdo-forma, um elemento fundamental é a questão do indivíduo, do individual nesse processo coletivo. Esse processo, ao mesmo tempo em que incentiva o trabalho coletivo, garante a individualidade dos agentes que, em função da sua experiência 
pessoal, da sua prática "individual", têm condições de criar, de produzir, enfim, de se colocar enquanto agente ator e autor do processo e do conhecimento deles resultantes. Deixa de ser um elemento receptivo e passa a ter uma atitude ativa, garantindo, assim, a sua individualidade. $O$ processo favorece ao indivíduo um desenvolvimento em função daquilo que ele é e não daquilo que os outros querem que ele seja.

As sistematizações da Didática prática até aqui produzidas, no período de 1985 a 2000, apontam para um modelo aberto de Didática em busca de novas práticas. Ultrapassa a transmissão do conhecimento, colocando pesquisa-ensino como unidade. Amplia as relações sociais coletivas e solidárias, redefinindo o entendimento da relação conteúdo-forma no ensino. Considera a importância do individual nos processos coletivos de ensinar. Entendendo que a sistematização teórica na área decorre da prática social historicamente situada e, portanto, que é a prática que vai definir novas sistematizações, continuo acompanhando o curso da história, auscultando-a e interrogando-a, pois “a resposta é sempre um trecho do caminho que está atrás de você. Só uma pergunta pode apontar o caminho para frente" (JOSTEIN,1977, p. 27).

\section{Notas}

1 No momento, o Grupo de Pesquisa Paradigmas Educacionais e Formação de Professores, cadastrado no CNPQ pela Área de Educação da PUCPR está desenvolvendo uma pesquisa junto aos egressos do Mestrado em Educação da PUCPR, para avaliar o impacto da formação pedagógica na prática docente dos seus egressos.

2 Esse contato se deu nos cursos de Pós-Graduação Lato Sensu da PUCMG, que reúne professores de todas as partes do país, além de cursos ministrados em vários estados, a convite das instituições de Ensino Superior.

3 No corpo do presente trabalho estarei utilizando a expressão Didática prática para me referir à prática pedagógica vivida pelo professor no interior da instituição escolar, suas iniciativas, avanços e recuos.

4 Preocupação que passa a ocupar espaço nos meios educacionais a partir da década de 80 .

5 Os professores envolvidos no processo de pesquisa-ensino produzem cadernos com relatos de experiências e artigos com relatos analíticos de práticas pedagógicas desenvolvidas em suas áreas de conhecimento, após a realização das disciplinas e/ou encontros pedagógicos. Essas produções são disponibilizadas nas bibliotecas das suas instituições de ensino e incluídas na bibliografia dos cursos que ministro. 


\section{Referências}

JOSTEIN, Gaarder. Ei! Tem alguém aí? Tradução de Isa Mara Sando. São Paulo, SP: Companhia das Letrinhas, 1977.

BERNARDO, João. Marx crítico de Marx. Porto: Enfrentamento, 1977. v. 1.

MARTINS, P. L O A Didática na atual organização do trabalho: uma experiência metodológica. Belo Horizonte, 1985. Dissertação (Mestrado) Faculdade de Educação/UFMG, 1985.

- Didática teórica/didática prática. para além do confronto. 7. ed. São Paulo, SP: Loyola, 2002.

. ADidática e as contradições da Prática. 2. ed. Campinas: Papirus, 2003.

A relação conteúdo-forma: expressão das contradições da prática pedagógica na escola capitalista. In: VEIGA, I. P. A Didática: o ensino e suas relações. 7. ed. Campinas, Papirus, 2003. p. 77-103.

Recebido em 03/04/2003

Aprovado em 15/08/2003 